\title{
Estimation of Economic System's Proportional Development Using Economic Growth Model
}

\author{
Gavriil A. Agarkov', a), Tatyana V. Tarasyeva ${ }^{1,2, b)}$ \\ ${ }^{1}$ Ural Federal University, 620002, Mira Street, 19, Ekaterinburg, Russia \\ ${ }^{2}$ Institute of Economics of the Ural Branch of the Russian Academy of Sciences, 620014, Moskovskaya Street, 29, \\ Ekaterinburg, Russia \\ a)Corresponding author: g.a.agarkov@urfu.ru \\ b)tataponomaryova@mail.ru
}

\begin{abstract}
Sustainable development of socio-economic systems at various levels is now a major research topic. The relevance of this topic lies in the scale and importance of the tasks, included in the process of ensuring the sustainability of the economic systems development. One of the most important components of socio-economic systems the sustainable development is to ensure its economic security. The process of ensuring the economic security of the region is in maintaining a stable functioning of the territory, with the constant improvement of the socio-economic situation. The main parameters of the development of the socio-economic system affect the process of achieving economic security in the region. These parameters must be determined and predicted to adjust the functioning of the socio-economic system of the region. To simulate the level and dynamics of GRP indicators, capital per employee, as well as the optimal investment plan, we used the model of economic growth of R. Solow. The considered model combines classical constructions of the theory of economic growth and modern methods for analyzing the theory of optimal control, in particular, generalizing the Pontryagin maximum principle for problems with an infinite planning horizon. Investments in fixed capital are the control parameter in the model, which allows ensuring the growth of output through the production function. Thus, the use of modification of the Solow model will allow to predict the dynamics of the main macroeconomic indicators for the subjects in the short and long term, as well as to assess the potential of the regions to ensure sustainable proportional development.
\end{abstract}

Keywords: integrated assessment, economic growth, economic security, economic system, economic sustainability, internal immunity, labor market.

\section{INTRODUCTION}

Problems of sustainable development of regional socio-economic systems at the present stage of economic development of the country is the object of public administration and research. Given the specificity of the territorial structure of Russia as a federal state, it should be noted that each region of the Russian Federation is unique for reasons of different geographical conditions, historical and cultural characteristics, etc., which confirms the need to study the problems of sustainable development in the context of regional systems. The International Commission on Environment and Development (Brundtland Commission) in 1987 first used the term "sustainable development". Sustainable development is a development that meets the needs of the present without compromising the ability of future generations to meet their needs.

Sustainable development implies development in the economic, political, social and environmental spheres that ensures the internal balance and progressive movement of the region as a whole, balanced by sectors of the economy, natural resources and population groups. Studies of the theoretical foundations of sustainable development of regional systems, as the basis of this process, describe economic security as a criterion for the sustainable functioning of the territory. On the other hand, it is necessary to continuously improve the socio-economic situation of regional systems, which is of particular importance in the context of the instability of the economic situation that arises both due to violations of the internal order and due to external threats.

International Conference of Numerical Analysis and Applied Mathematics ICNAAM 2019

AIP Conf. Proc. 2293, 120003-1-120003-4; https://doi.org/10.1063/5.0030881

Published by AIP Publishing. 978-0-7354-4025-8/\$30.00 
Economic security is a set of economic, geological, environmental, legal and other conditions that provide the prerequisites for its survival in crisis conditions, as well as the protection of vital interests of the state in relation to its resource potential and the dynamics of growth and development. It is also necessary to create internal and external protection from destructing influences, to ensure the development of competitiveness in world markets and the stability of the financial situation. Formation of economic security as a condition for achieving sustainable development of a regional socio-economic system is a complex and multi-level process, depending on a number of parameters. It is necessary to identify and predict these parameters to adjust the functioning of the socio-economic system of the region.

\section{THEORETICAL FRAMEWORK}

The task is to provide the macroeconomic indicators necessary for assessing the passive economic security of regions. We decided to dwell on models of economic growth. A distinctive feature of these models is the possibility of building short-term forecasts of high accuracy for a complex of macroeconomic indicators of both countries and regions, such as GRP, the level of investment in fixed capital, the availability of fixed assets and the number of employed people. Economic science at the present stage has two theories of economic growth: namely, NeoKeynesian and Neoclassical theories, which determines the use of two types of models that characterize these theories.

Within the framework of the Neo-Keynesian trend, the factors that determine, first, the volume and dynamics of national income, and second, the volumes of consumption and savings, are to be studied. The neoclassical direction bases on the idea of the equilibrium of an optimal market system, which regards as an ideal self-regulating mechanism. In the real economy, such an equilibrium is practically impossible to achieve. However, when modeling equilibrium, it becomes possible to correct the deviation of real economic processes from ideal ones. Also within the neoclassical direction, the works of Robert Solow are of great importance for the development of the theory of economic growth. In his studies, R. Solow modified the Cobb-Douglas function by taking into account an additional factor in the model - the level of technology development.

To simulate the dynamics of the main economic indicators we applied the model of optimal economic growth, aimed at analyzing the dynamics of the growth of the gross regional product (GRP) of the country, defined as the market value of all goods and services produced in the region during the year. In the model, we have two resulting factors used in production: fixed capital and labor. The output depends on these factors through the Cobb-Douglas production function.

\section{ECONOMIC GROWTH MODEL}

The need to maintain a safe development of the economy is due to two components that form the generalized structure of the concept of "economic security": ensuring the prerequisites for economic growth, improving the level and quality of life of the population of the region. In this regard, it is necessary to forecast the macroeconomic indicators of the region. Analysis of the simulation results of macroeconomic indicators will provide a reliable assessment of the potential susceptibility of the regional system to the consequences of external threats.

The modeling of indicators of the level and dynamics of GRP, capital (fixed assets) per employee, as well as the optimal investment plan was carried out using the R. Solow model of economic growth $[2,4]$. The considered model under takes into account classical constructions of the theory of economic growth [4] and modern methods for analyzing the theory of optimal control [3], in particular, generalizing the Pontryagin maximum principle for problems with an infinite planning horizon. Investments in fixed capital are the control parameter in the model, which allows ensuring the growth of output through the production function.

The model takes into account three factors: the size of capital $K(t)$, labor $L(t)$ at time $t$, and also the volume of output $Y(t)$, which is given by the equation $Y(t)=F(K(t), L(t))=a K^{\alpha}(t) L^{1-\alpha}(t) . F(K(t), L(t))$ denotes the production function of the Cobb-Douglas exponential type [9]. To go to the relative values of the considered factors, the production function (1) is used:

$$
y(t)=\frac{Y(t)}{L(t)}=\frac{F(K(t), L(t))}{L(t)}=F\left(\frac{K(t)}{L(t)}, 1\right)=f(k(t))=a k^{\alpha}(t),
$$

where $y(t)=f(k(t))$ is labor productivity depending on the capital-labor ratio. 
As a simplification, within the framework of this model, a closed economic system is considered, i.e. the issue depends only to consumption and investment. In this connection, the balance ratio (2) is:

$$
Y(t)=C(t)+I(t)=C(t)+u(t) \cdot Y(t) \Rightarrow c(t)=\frac{C(t)}{L(t)}=y(t) \cdot(1-u(t)),
$$

where $C(t)$ - the level of consumption;

$I(t)$ - the volume of investment in fixed assets at the time;

$c(t)$ - is the level of consumption per worker;

$u(t)$ - the share of GRP invested in fixed assets.

A modification of the growth model of Solow assumes that changes in the capital fund $K(t)$ occur according to the following equation (3):

$$
\dot{K}(t)=u(t) \cdot Y(t)-\mu \cdot K(t), K(0)=K_{0}, \frac{\dot{L}(t)}{L(t)}=n, L(0)=L_{0},
$$

where $\mu$ - the rate of depreciation of capital; $n$ - relative level of change in labor $L(t)$.

In the transition to relative values, the dynamics of the indicator $k(t)$ is expressed by the following equation (4):

$$
\dot{k}(t)=u(t) f(k(t))-\delta k(t), \quad k(0)=k_{0}=\frac{K_{0}}{L_{0}},
$$

where $\delta=\mu+n$ is the degree of dilution of capital occurring due to its depreciation and the increase in the volume of labor.

Another feature of the modification of the Solow model is the consideration of the problem of optimal investment management. Within the framework of this task, the target functional equals to an integral of the logarithmic consumption index discounted over an infinite period of time (5):

$$
J(\cdot)=\int_{0}^{+\infty} e^{-\rho t} \ln c(t) d t=\int_{0}^{+\infty} e^{-\rho t}(\ln f(k(t))+\ln (1-u(t))) d t,
$$

where $\rho$ is the discounting factor.

In utility theory, the logarithmic function describes the relative increase in consumption per unit of time. In conditions of uncertainty, this function sets a constant relative risk aversion. In this connection, the task of building an investment strategy arises, which maximizes the target functional on the trajectories of a dynamic system. There is a single optimal strategy that achieves a stable state at a stationary point with coordinates $\left(k^{*}, t^{*}\right)$, where:

$$
k^{*}=\left\{\begin{array}{l}
\left(\frac{a \alpha}{\delta+\rho}\right)^{\frac{1}{1-\alpha}}, u^{*}=\frac{\alpha \delta}{\delta+\rho}<u, \\
\left(\frac{u a}{\delta}\right)^{\frac{1}{1-\alpha}}, u^{*}=u,
\end{array}\right.
$$

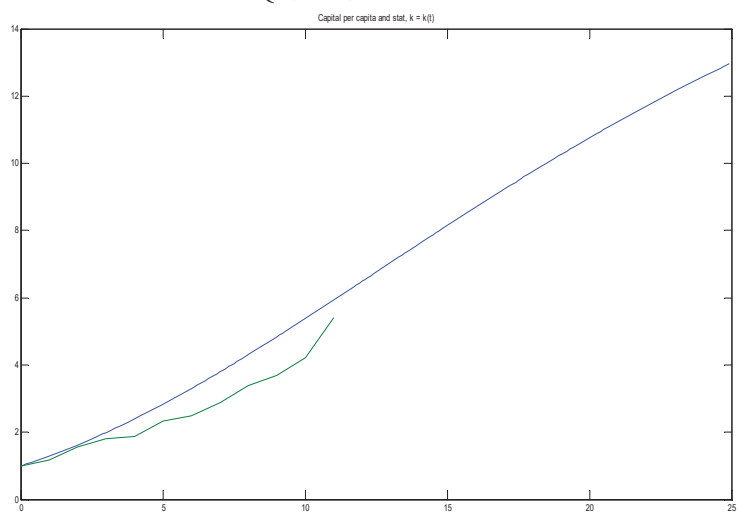

(a)

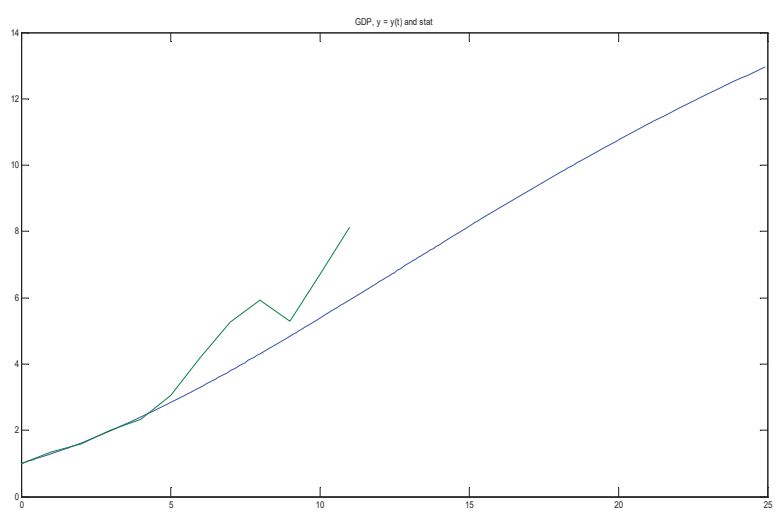

(b)

FIGURE 1. (a) Forecast of capital per person employed, (b) GRP forecast in the Sverdlovsk region. 
If fixed capital investment satisfies the restriction $u^{*}<u$, over time its level drops to $u^{*}$. Otherwise, the level of investment will be maximal over the entire time interval up to the point of stabilization of the dynamic system. Dynamic trajectories built for this system have a pronounced $S$-shape, regardless of the development scenario, which is provided by the parameter $\bar{u}$ that limits the level of investment $u(t)$. In addition, the optimal trajectories have a tendency of growth saturation $[1,3]$.

Using the modification of the Solow economic growth model will allow to predict the dynamics of the main macroeconomic indicators in the near future for the regions, as well as to assess the potential of the regions to ensure sustainable proportional development over a certain period. These provisions are of practical importance in the conditions of the influence of external factors destabilizing the regional economy.

\section{CONCLUSION}

We considered the economic security as a set of economic, geopolitical, environmental, legal and other conditions that provide the prerequisites for its survival in the event of a crisis and future development. It is necessary to protect the vital interests of the state with regard to its resource potential, balance and dynamics of development and growth. It requires the creation of internal immunity and external protection from destabilizing effects. At the same time, it is necessary to increase competitiveness in world markets and the stability of its financial situation, as well as to create of decent living conditions and, as a consequence, to ensure harmonious development of economic systems.

To develop corrective measures to ensure sustainable development of the region and its economic security, it is necessary to develop a forecast of the main macroeconomic indicators. We used a modification of the Solow economic growth model for forecasting. This modification allows analyzing the dynamics of the growth of the gross regional product (GRP) of the subjects, forecasting the dynamics of the value of fixed assets (capital) per employee, the optimal level of investment for the short and long term.

Thus, the use of the Solow model modification makes it possible to forecast the dynamics of the main macroeconomic indicators for subjects in the short and long term, as well as to assess the potential of the regions to ensure sustainable proportional development within a certain period. These provisions are of practical importance in the conditions of the influence of external factors destabilizing the regional economy.

\section{ACKNOWLEDGEMENTS}

The work was supported by Act 211 Government of the Russian Federation, contract № 02.A03.21.0006.

\section{REFERENCES}

[1] Aseev, S.M., Kryazhimskiy, A.V. (2007). The Pontryagin Maximum Principle and Optimal Economic Growth Problems. Proceedings of the Steklov Institute of Mathematics, Pleiades Publishing. Vol. 257.

[2] Krasovskii A., Kryazhimskiy A., Tarasyev A. (2008). Optimal Control Design in Models of Economic Growth. Evolutionary Methods for Design, Optimization and Control (P. Neittaanmäki, J. Périaux and T. Tuovinen, Eds.), CIMNE, Barcelona, Spain. pp. 70-75.

[3] Pontryagin L.S., Boltyansky V.G., Gamkrelidze R.V., Mishchenko E.F. (1976). Mathematical theory of optimal processes. M.: Science.

[4] Solow R.M. (1970). Growth Theory: An Exposition. NY, Oxford Univ. Press.

[5] Tarasyev A.M., Usova A.A. (2012). Stabilization of the Hamiltonian system for the construction of optimal trajectories. Proceedings of the Mathematical Institute. V.A. Steklova. Vol. 277. pp. 257-274. 